\title{
Editorial Regarding: Practical Treatment of Lewy Body Disease in the Clinic: Patient and Physician Perspectives
}

Thomas Müller

Received: February 27, 2018 / Published online: April 27, 2018

(C) The Author(s) 2018

Keywords: Alzheimer's disease; Lewy body dementia; Parkinson's disease dementia

Alzheimer's disease, Lewy body dementia, Parkinson's disease dementia, vascular dementia, and vascular Parkinsonism are frequently occuring syndromes of chronic brain neurodegeneration. They cause an enormous burden for healthcare. All these terms reflect disease entities; in other words, they are not specific, and their features and progression overlap. Thus, their drug treatment needs an individually adapted not a standardised regimen.

Therefore, in academia, specific well-defined diagnosis criteria only partially and artificially reflect the whole spectrum of signs observed in the clinic. Drug treatment of these patients

Editorial regarding the article by Londos, E., Neurol Ther (2017) https://doi.org/10.1007/s40120-017-0090-8, Letter to the Editor by Brzezicki, M., Neurol Ther (2018) https://doi.org/10.1007/s40120-018-0098-8 and Author's Response: Londos, E., (2018) https://doi.org/10. 1007/s40120-018-0099-7.

Enhanced digital content To view enhanced digital content for this article go to https://doi.org/10.6084/ m9.figshare.6099452.

T. Müller (凹)

Department of Neurology, St. Joseph Hospital Berlin-Weissensee, Gartenstr. 1, 13088 Berlin, Germany

e-mail: th.mueller@alexianer.de;

thomas.mueller@ruhr-uni-bochum.de focuses on the amelioration of the quality of life for patients and their caregivers, quite often only trying to delay life in a nursing home. Standardised guidelines based on so-called evidence-based analyses of trials are of limited value. Off-label use of drugs is common.

One should not forget that the employed assessment instruments, as in this case, are only sensitive and valuable to a certain extent. In this respect, the MiniMentalStateExamination represents just a screening tool, which is overestimated and therefore under debate $[1,2]$. Performance of these tests suffers from additional factors, such as motivation, education and personality features.

Moreover, the onset and features of these syndromes of cholinergic and dopaminergic deficiency are heterogeneous; pure forms rarely exist. The most common form is a mixture of all the discussed syndromes, often based on a predominant vascular origin. Mostly, patients also suffer from additional disorders, which may aggravate or even induce cognitive dysfunction, or falsely imitate cognitive deterioration, i.e. in the case of the additional onset of depression or apathy.

To date, it is far from clear whether Lewy body accumulation or ß-amyloid or tau protein enrichment play any active role in the ongoing chronic disease process itself in the affected neurons. They may also just represent well-wrapped protein garbage as a consequence of disease-affected neurons [3]. Chronic neurodegeneration is 
a result of different metabolic cascades. They finally end up in cell death-inducing events and, accordingly, individually different clinical signs. Nowadays, research on the causes of neurodegeneration still focus on hypotheses based on neuropathological findings. Many of them support the concepts of protein misfolding. Generally, when protein misfolding occurs, the first line of defense involves refolding, a process mediated by chaperone proteins. If the process of refolding fails, these misfolded proteins will either be degraded or will accumulate. When the refolding/ degradation machinery is unable to process misfolded proteins, a stress response is activated that involves upregulation of refolding and degradation processes [4]. If the misfolded protein stress is too severe, cell death programs may be activated. Accordingly, potential strategies are the reduction of protein misfolding, the repair of misfolded proteins and the facilitation of the degradation of proteins which are thus damaged without any chance for repair. However, there is a certain capacity of the human brain to compensate these initial events for a considerable interval before the clinical onset of initial mild and unspecific symptoms of neurodegenerative disease. Thus, the velocity of disease progression also differs in an individually different manner. Preclinical and experimental researchers still primarily focus on the acetylcholine-respectively, dopamine deficit and related behavioural changes. They do not consider the individually different decline of other neurotransmitter systems, like 5-HT, norepinephrine, etc. These are the main reasons why therapeutic interventions on tau- and B-amyloid metabolism has failed in clinical trials.

In this respect, the discussion here [5-7] is a typical example of the missing reality of academic research and so-called evidence-based medicine for the daily maintenance of these patients.

\section{ACKNOWLEDGEMENTS}

Funding. No funding or sponsorship was received for this study or publication of this article.
Authorship. All named authors meet the International Committee of Medical Journal Editors (ICMJE) criteria for authorship for this article, take responsibility for the integrity of the work as a whole, and have given their approval for this version to be published.

Disclosures. Thomas Müller has nothing to disclose.

Compliance with Ethics Guidelines. This article is based on previously conducted studies and does not contain any studies with human participants or animals performed by any of the authors.

Open Access. This article is distributed under the terms of the Creative Commons Attribution-NonCommercial 4.0 International License (http://creativecommons.org/licenses/ by-nc/4.0/), which permits any noncommercial use, distribution, and reproduction in any medium, provided you give appropriate credit to the original author(s) and the source, provide a link to the Creative Commons license, and indicate if changes were made.

\section{REFERENCES}

1. Larner AJ. Correlation or limits of agreement? applying the Bland-Altman approach to the comparison of cognitive screening instruments. Dement Geriatr Cogn Disord. 2016;42(5-6):247-54.

2. Seigerschmidt E, Mosch E, Siemen M, Forstl H, Bickel $\mathrm{H}$. The clock drawing test and questionable dementia: reliability and validity. Int J Geriatr Psychiatry. 2002;17(11):1048-54.

3. Sian-Hulsmann J, Monoranu C, Strobel S, Riederer P. Lewy bodies: a spectator or salient killer? CNS Neurol Disord Drug Targets. 2015;14(7):947-55.

4. Kumar P, Jha NK, Jha SK, Ramani K, Ambasta RK. Tau phosphorylation, molecular chaperones, and ubiquitin E3 ligase: clinical relevance in Alzheimer's disease. J Alzheimers Dis. 2015;43(2):341-61.

5. Londos E. Practical treatment of lewy body disease in the clinic: patient and physician perspectives. Neurol Ther. 2017. https://doi.org/10.1007/s40120-017-0090-8. 
6. Brzezicki MA, Kobetić MD. Letter to the editor regarding: practical treatment of Lewy body disease in the clinic: patient and physician perspectives. Neurol Ther. 2018. https://doi.org/10.1007/s40120018-0098-8.
7. Londos E. Author's response to the letter to the editor regarding: practical treatment of Lewy body disease in the clinic: patient and physician perspectives. Neurol Ther. 2018. https://doi.org/10.1007/s40120-018-0099-7 